\title{
Prevalence of COVID-19 Infection and Its Associated Factors Among Government Healthcare Workers (HCWs) in Lahad Datu, Sabah
}

\author{
Nur Syarah Zulaikha, M.R. ${ }^{1,}$ Anita, A.R. ${ }^{1 *}$, Siti Aisah, M. ${ }^{1,}$ Valentine, G. ${ }^{2}$ \\ 1 Department of Community Health, Faculty of Medicine and Health Sciences, University Putra Malaysia, UPM \\ Serdang, Selangor, Malaysia \\ 2 OSH Unit, Sabah State Health Department, Ministry of Health, Malaysia \\ *Corresponding author. Email: anitaar@upm.edu.my
}

\begin{abstract}
The increase in Coronavirus disease 2019 (COVID-19) cases involving healthcare workers (HCWs) raises concern and puts a burden on government health services due to the reduced availability of functional workforce despite increasing workload demand. To determine the prevalence of COVID-19 infection and its associated factors among government healthcare workers (HCWs) in Lahad Datu, Sabah. This was a cross sectional design study conducted in May 2021 among 440 government healthcare workers that had undergone COVID-19 testing at least once in Lahad Datu, Sabah. Validated Google form questionnaire were administered in this study. All data were analyzed by SPSS version 25 involving descriptive statistic and analytical statistic using Chi Square test and multiple logistic regression analysis. The response rate was $81.1 \%$. The prevalence of COVID-19 infection among government HCWs in Lahad Datu, Sabah was 8.7\%. Types of COVID-19 exposure ( $p<0.05$ ), staying in same household as a person with COVID-19 ( $<<0.05)$, had direct physical contact with HCWs with COVID-19 without wearing appropriate $\operatorname{PPE}(\mathrm{p}<0.01)$, had contact with environment where a COVID-19 patient received care without wearing appropriate PPE ( $\mathrm{p}<0.01$ ), did not adhere to physical distancing more than 1 metre with unknown COVID-19 patient infection status $(\mathrm{p}=0.02)$ and infection, prevention and control (IPC) training status $(p<0.05)$ were factors associated with COVID-19 infection among government healthcare workers in Lahad Datu, Sabah. There were four factors that were able to predict COVID 19 infection among government healthcare workers in Lahad Datu, Sabah which were community-related exposure (AOR 34.87; 95\% CI 8.60-141.35, p < 0.01), healthcare-related exposure (AOR 6.37; 95\% CI 1.94-20.85, p < 0.01), has direct physical contact with HCWs with positive COVID-19 without wearing PPE (AOR 6.96; 95\% CI 2.04-23.73, p < 0.01), and had IPC training after COVID-19 pandemic (AOR 11.99; 95\% CI 1.63-88.16, $\mathrm{p}=0.02$ ). Community-related exposure, healthcare-related exposure, had direct physical contact with HCWs with positive COVID-19 without wearing PPE and had IPC training after COVID-19 pandemic is associated with increased risk of COVID-19 infection in this study. The increased COVID-19 infection risk among HCWs that had IPC training after COVID-19 pandemic was mainly due to the fact that more HCWs with completed training were dispatched to COVID-19 management services centres thus they had more COVID-19 exposure from patients. Healthcare workers are among the population at risk of getting COVID-19 infection due to their work nature. Therefore, adhere to appropriate PPE use and physical distancing in the community and workplaces, also having regular and updated COVID-19 related training can reduce COVID-19 infection in healthcare workers.
\end{abstract}

Keywords: COVID-19, healthcare workers, Lahad Datu

\section{INTRODUCTION}

The Coronavirus disease (COVID-19) pandemic contributes to the significant impact of health, social and economic worldwide. The pandemic is causing more than 100 million confirmed positive cases and more than 2.1 million deaths globally until January 2021, and the number keeps rising [1]. The pandemic was first recognized in Wuhan, the capital city of Hubei province of China, in December 2019 and tremendously causing significant communicable disease impacts globally now [2]. This virus is highly infectious and easily transmitted with high basic reproductive number $\left(\mathrm{R}_{0}\right)$ [3]. Subsequently, on 13 January 2020, Thailand reported the first COVID-19 case outside China, just two days after China reported its first COVID-19 death on January 11, 
2020 [4]. The first positive COVID-19 case in Malaysia was reported on January 25, 2020, an imported case involving a non-local patient from Wuhan, China [5]. Later on, the first local positive COVID-19 case was reported on February 3, 2020, with travel history to a neighbouring country for a business meeting, which was also attended by a delegation from China, becoming the starting point of the First Wave of COVID-19 in Malaysia [5]. Since then, the numbers of COVID-19 in Malaysia keep increasing. Currently, Malaysia is still in the midst of dealing with the Third Wave of COVID-19 infections which started in September 2020 with more than 2.5 million COVID-19 cases were reported until November 2021 [6]. The early phase of Third Wave of COVID-19 in Malaysia had put Sabah as the highest state with COVID-19 cases in Malaysia. Throughout the year 2020, Sabah reported highest COVID-19 cases (32.6\%), followed by other states. The two main factors for the high number of COVID-19 cases in Sabah were attributed by Lahad Datu Benteng Cluster and 2020 Sabah State Election.

Protecting healthcare workers (HCWs) is a vital element of strategic response towards the COVID-19 pandemic, especially as the healthcare system is in critical need to cope with the high surge of COVID-19 patients. The World Health Organization (WHO) and Ministry of Health (MOH) have published and distributed guidelines [7] for healthcare workers (HCWs) for managing COVID-19 patients, which recommending comprehensive safety protocols for healthcare workers (HCWs) such as using proper personnel protective equipment (PPE) [8]. However, as the recommended infection control precautions may not have been adequate to prevent the spread of the COVID-19 infections among HCWs, multiple unrecognised factors may contribute to the virus transmission in government health facilities [9]. Elderly [10], people with underlying comorbidities and immunocompromised are vulnerable to COVID-19 infection [11]. The WHO mentioned that factors associated with COVID-19 infection among HCWs are due to long working hours, sub-optimal adherence and low awareness to infection protocol control, inadequate or insufficient PPE and infection control training, working in the higher-risk department are other considered factors [8].

\section{METHOD}

\subsection{Study design and participants}

This was a cross sectional design study conducted in May 2021 among 440 government healthcare workers that had undergone COVID-19 testing at least once in Lahad Datu, Sabah. The COVID-19 diagnosis was confirmed by real-time polymerase chain reaction (rtPCR) and Rapid Test Kit-Antigen (RTK-Ag) done on the respondents from March 2020 until $1^{\text {st }}$ May 2021. Only healthcare workers present in Lahad Datu during the period of data collection included while those who did not consent for participation were excluded. The data collection was done in May 2021 using a validated Google form questionnaire. The link to the Patient Information Sheet (PIS) and the questionnaire were disseminated to the healthcare workers through their Head of Departments after obtaining permission from the Head of the Hospital and Head of Health District Office and participants were not required to sign in to any account to fill in the questionnaire. This study was conducted after receiving approval from the Medical Review \& Ethics Committee (MREC), Ministry of Health Malaysia (NMRR-20-3153-57830(IIR)) and Ethics Committee for Research Involving Human Subjects of Universiti Putra Malaysia (JKEUPM). Permission to conduct this study was sought from Jabatan Kesihatan Negeri Sabah, Pejabat Kesihatan Kawasan Lahad Datu and Hospital Lahad Datu. The participants' anonymity was maintained throughout this study to ensure that this research is carried out ethically.

\subsection{Statistical analysis}

Descriptive and analytical analysis was used to characterize the study population using SPSS Version 25.0. Descriptive data were compiled and reported in frequency and percentage. The Chi-Square test and Fischer's Exact test were used to analyze categorical variables and the associations are presented as $\mathrm{x}^{2}$ with 95\% confidence interval (CI). Multiple logistic regression was performed using Forward LR method to identify predictors associated with COVID-19 infection among government HCWs in Lahad, Datu, Sabah and the data are presented as adjusted odds ratio (AOR) with $95 \%$ CI. All p-values less than 0.05 were considered statistically significant.

\section{RESULTS}

\subsection{Demographics and baseline characteristics}

From 440 respondents from both hospital and primary healthcare settings, 384 respondents answered the questionnaire. We excluded those who did not completed the survey $(\mathrm{n}=27)$ resulting in a final sample of 357 respondents. The prevalence of COVID-19 infection among government HCWs in Lahad Datu, Sabah was $31(8.7 \%)$ with $21(67.7 \%)$ presented with symptoms. Majority of the respondents were in age group 30-39 years old $(49.0 \%)$, female (66.1\%), Bumiputera Sabah (73.7\%), had underlying medical illness/es (17.9\%), worked in primary healthcare settings $(72.5 \%)$, working simultaneously in both COVID-19 and non-COVID-19 area $(62.2 \%)$, nurses $(43.4 \%)$ and had no prior COVID19 exposure while working (47.6\%) followed by healthcare related exposure $(46.2 \%)$. The adherence rate for using appropriate PPE (82.1\% until 90.2\%) was higher compared to adherence rate of physical distancing ( $<1$ meter) $(69.5 \%$ until $82.9 \%)$. Also, majority of them 
had IPC training before and after COVID-19 pandemic started (64.7\%). (Table 1)

Table 1. Baseline Characteristics of Respondents

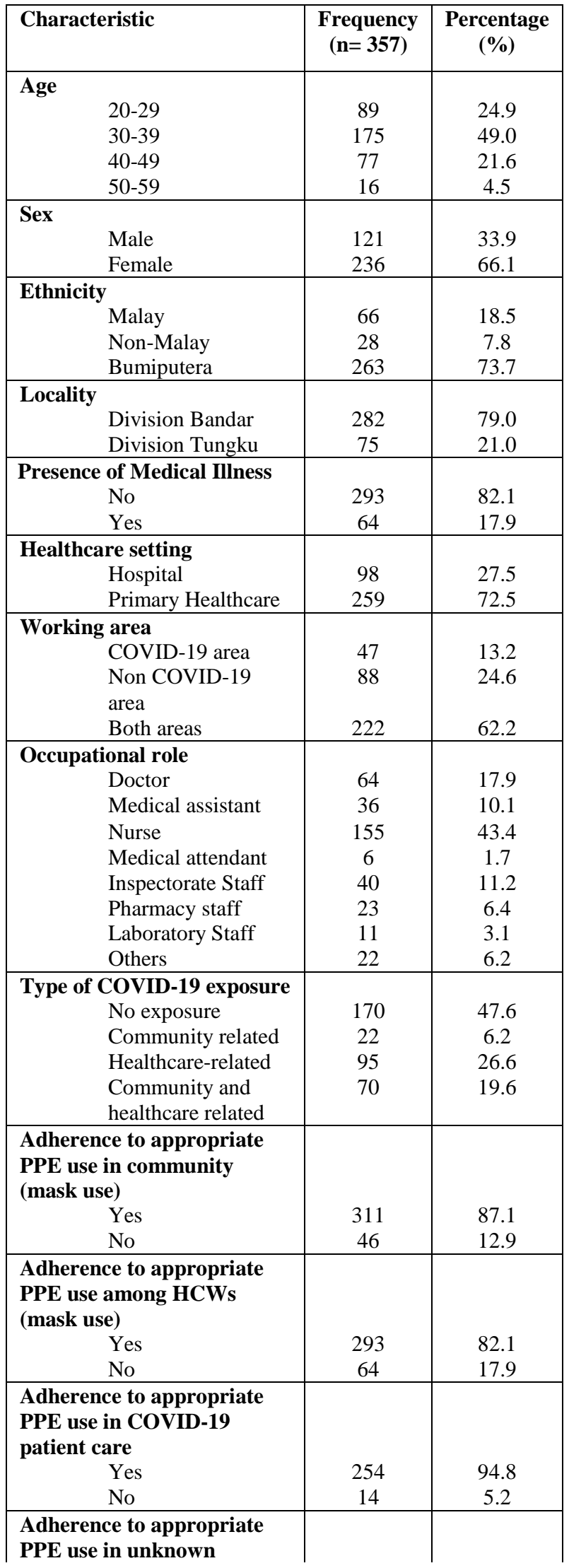

\begin{tabular}{|c|c|c|}
\hline Characteristic & $\begin{array}{c}\text { Frequency } \\
(n=357)\end{array}$ & $\begin{array}{c}\text { Percentage } \\
(\%)\end{array}$ \\
\hline $\begin{array}{l}\text { COVID-19 patient infection } \\
\text { status management } \\
\text { Yes } \\
\text { No }\end{array}$ & $\begin{array}{c}322 \\
35\end{array}$ & $\begin{array}{c}90.2 \\
9.8\end{array}$ \\
\hline 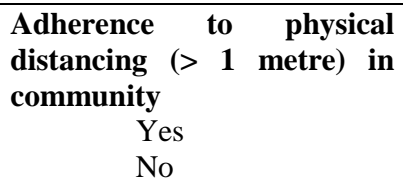 & $\begin{array}{c}260 \\
97\end{array}$ & $\begin{array}{l}72.8 \\
27.2\end{array}$ \\
\hline $\begin{array}{l}\text { Adherence to physical } \\
\text { distancing (> } 1 \text { metre among } \\
\text { HCWs) } \\
\text { Yes } \\
\text { No }\end{array}$ & $\begin{array}{l}248 \\
109\end{array}$ & $\begin{array}{l}69.5 \\
30.5\end{array}$ \\
\hline $\begin{array}{l}\text { Adherence to physical } \\
\text { distancing (> } 1 \text { metre) with } \\
\text { unknown COVID-19 } \\
\text { patient infection status } \\
\text { Yes } \\
\text { No } \\
\end{array}$ & $\begin{array}{c}296 \\
61 \\
\end{array}$ & $\begin{array}{l}82.9 \\
17.1 \\
\end{array}$ \\
\hline $\begin{array}{l}\text { IPC training status } \\
\text { No training } \\
\text { Before COVID-19 } \\
\text { pandemic } \\
\text { After COVID-19 } \\
\text { pandemic } \\
\text { Before and after } \\
\text { COVID-19 } \\
\text { pandemic started }\end{array}$ & $\begin{array}{r}46 \\
32 \\
48 \\
231\end{array}$ & $\begin{array}{c}12.9 \\
9.0 \\
\\
13.4 \\
64.7\end{array}$ \\
\hline
\end{tabular}

\subsection{The association and predictors for COVID- 19 infection among respondents}

The Chi-square analysis showed that there was significant association between six (6) variables and COVID-19 infection among respondents (Table 2). There were significant association between type of COVID-19 exposure $(\mathrm{p}=<0.01)$, staying in same household as a person with COVID-19 $(\mathrm{p}<0.05)$, having direct physical contact with HCWs with COVID-19 without wearing appropriate PPE ( $\mathrm{p}<0.01)$, having contact with the environment where COVID-19 patient received care without wearing appropriate PPE (p < 0.01 ), adherence status to physical distancing $(>1$ metre) with unknown COVID-19 patient infection status $(\mathrm{p}=$ $0.02)$, IPC training status $(\mathrm{p}<0.05)$ and COVID-19 infection among government healthcare workers in Lahad Datu, Sabah.

This study also found four factors that were able to predict COVID-19 infection among government healthcare workers in Lahad Datu, Sabah which were community-related exposure (AOR 34.87; 95\% CI 8.60$141.35, \mathrm{p}<0.01$ ), healthcare-related exposure (AOR 6.37; 95\% CI 1.94-20.85, $\mathrm{p}<0.01$ ), has direct physical contact with HCWs with positive COVID-19 without wearing PPE (AOR 6.96; 95\% CI 2.04-23.73, $\mathrm{p}<0.01$ ), and had IPC training after COVID-19 pandemic (AOR $11.99 ; 95 \%$ CI 1.63-88.16, $\mathrm{p}=0.02)($ Table 2$)$. 
Table 2. Univariable and multivariable analysis of factors associated with COVID-19 infection among respondents

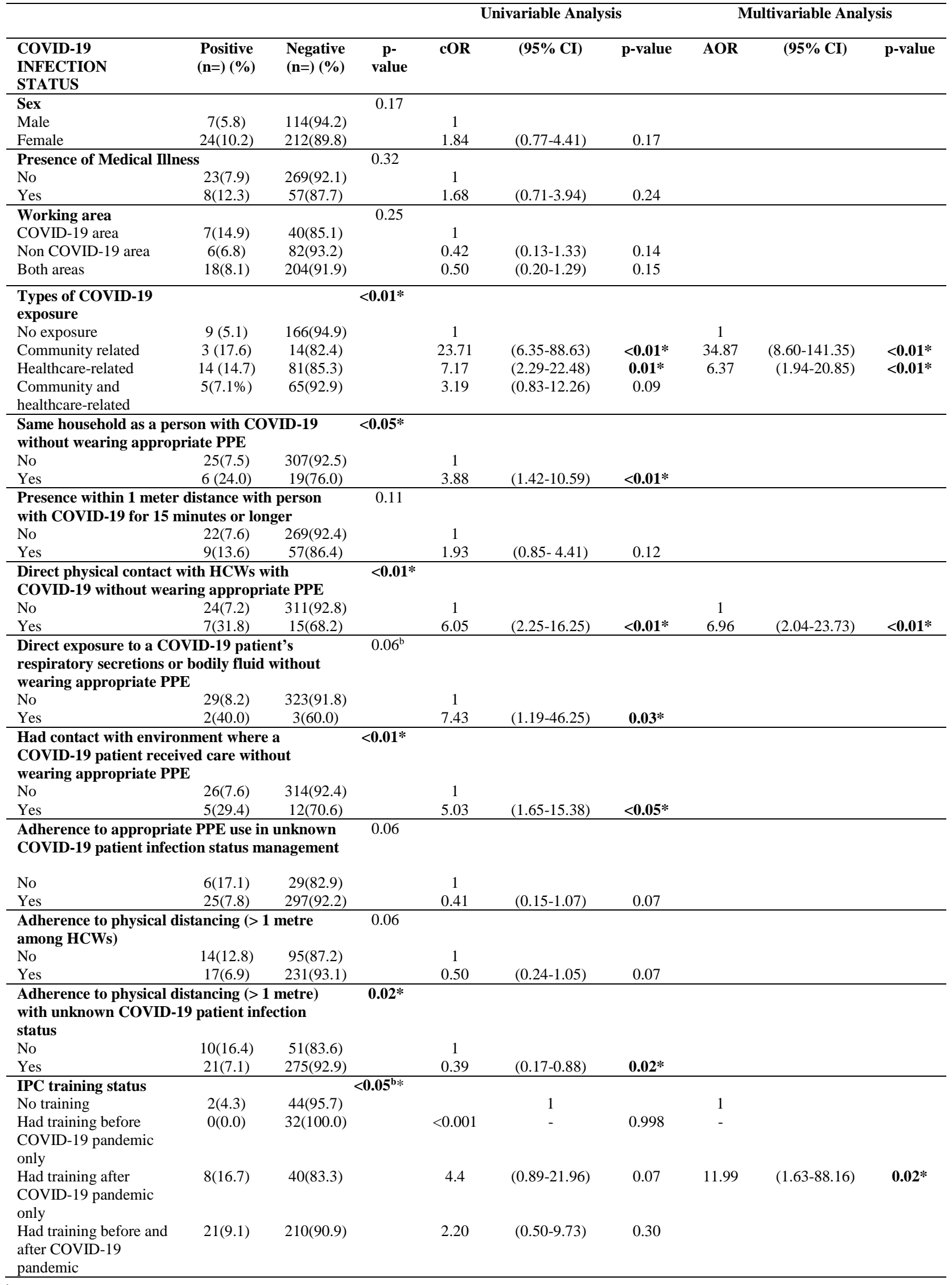

\footnotetext{
${ }^{\mathrm{b}}$ Fischer Exact Test $* \mathrm{p}$-value $<0.05$ is significant
} 


\section{DISCUSSION}

A total of $31 \mathrm{HCWs}$ were diagnosed with positive COVID-19 in this study, with a prevalence of $8.7 \%$ among respondents. A meta-analysis of $127,480 \mathrm{HCWs}$ globally also demonstrated an overall COVID-19 infection prevalence of $8.7 \%$ [12]. Another COVID-19 prevalence study in Malaysia showed a prevalence of 4.5\% among HCWs in non-COVID-19 designated cardiology centre in Sarawak [13]. The difference between the prevalence may be connected to the timing of the study, types of facility studied, the prevalence of COVID-19 in the specific community and difference in hospital policy or management. Our study was conducted in Sabah, second highest state, with COVID19 cases in Malaysia in May 2021. Moreover, health care services capacity in Lahad Datu comprises of a COVID19 managing hospital, six COVID-19 screening clinics, and a large quarantine station that showed significant healthcare workers involvement in the COVID-19 management activities and was the 4th highest district with COVID-19 cases when this study was conducted. These may explain the higher prevalence of $8.7 \%$ among government HCWs in Lahad Datu than other study among HCWs in Malaysia. The first positive COVID-19 case among respondents was only detected in September 2020 despite the COVID-19 pandemic already reached Lahad Datu since March 2020 was attributed to the sudden surge of COVID-19 cases due to Lahad Datu Benteng cluster and political campaign activities for the 2020 Sabah state election starting in late August 2020 [14]. Lahad Datu then drastically recorded 241 new cases within one month from $1^{\text {st }}$ September until $27^{\text {th }}$ September [15] and even declared as the only COVID-19 red zone in Malaysia on $7^{\text {th }}$ September 2020 due to the highest case surge in a day in Malaysia during that time [15]. Lahad Datu Benteng cluster recorded a total of 1,146 cases; 675 cases were of Malaysian nationality, and 471 cases were immigrants and the cluster was only announced to have ended on $14^{\text {th }}$ December 2020, almost four months from the detection of its first case. Meanwhile, the large people gathering for the 2020 Sabah state election campaign that started from 12 September 2020 and lasted until 26 September 2020, had contributed to the high COVID-19 cases. The Malaysia's Prime Minister had also emphasized the 2020 Sabah state election role in causing drastic surge of COVID-19 cases in Malaysia leading to the postponing of a smaller parliament election based on lesson learnt and the consequences procured by 2020 Sabah state election [16].

Most of the positive COVID-19 respondents were symptomatic $21(67.7 \%)$ with the most common symptoms were fatigue, headache, fever and muscle pain. Those symptoms are consistent with the global trend and as reported by the WHO (2020a); that the most common COVID-19 symptoms are fever, dry cough and fatigue followed by other less common symptoms. Another study done among positive COVID-19 HCWs in a district specialist hospital in West Malaysia, also reported that most of their respondent were symptomatic (87.7\%) and the most common symptoms were fever $(65.2 \%)$, sore throat (39.1\%) and cough (37.0\%) [17]. There was no respondent with Stage 5 COVID-19 infection in our study cohort reported. showed good clinical prognosis among the study cohort. This finding was consistent with a study that compared the general community and healthcare workers in New York, which demonstrated that HCWs were less likely to have severe COVID-19 infection and are less likely to be admitted into ICU compared to the general community as $\mathrm{HCWs}$ were commonly younger and have less underlying comorbidities compared to the general community [18].

The median (IQR) of age in this study was 32 years old (11) with female predominance $(66.1 \%)$ is similar with another study on HCWs done in Klang Valley that reported mean (SD) of age was 34.9 years old (7.8) with also female predominance (74.3\%) [19]. Most of our respondents were Bumiputera Sabah $(73.7 \%)$, worked in Division Bandar $(79.0 \%)$ and did not have underlying medical illness $(82.1 \%)$, worked in primary healthcare $(72.5 \%)$ and were nurses $(43.4 \%)$. Most of the respondents worked in the COVID-19 area (73.4\%) might reflect the significant burden of COVID-19 infection onto the government healthcare workers capacity in Lahad Datu, Sabah. The requirement for more HCWs workforces in the COVID-19 area increased significantly when the COVID-19 pandemic reached Lahad Datu. Even though the number of staff remains almost the same, the work burden increased with the establishment of the new quarantine stations, COVID-19 triaging and swabbing station requiring staff's allocation into a new working space environment. $47.6 \%$ of our respondents did not have prior COVID-19 exposure reflecting good adherence to infection control protocol among government healthcare workers in Lahad Datu, Sabah. However, those who had healthcare-related exposure $(26.6 \%)$ was higher than those who had community-related exposure $(6.2 \%)$ can be explained by less time and social activities being spent in community areas. New enforcement on COVID-19 related law such as restriction on public gathering, compulsory mask use in public, travel restriction (inter-district and inter-state) and kept rising numbers of COVID-19 patients demanding full attention from HCWs requiring most of the HCWs' times being consumed within the healthcare facilities.

Our study also showed a good percentage of adherence to appropriate PPE use among government HCWs, with an adherence percentage of more than $80 \%$. 
The highest adherence to appropriate PPE use percentage was during COVID-19 patient care (94.8\%), and the lowest adherence to appropriate PPE use percentage was among HCWs (mask use) (82.1\%). Good adherence percentage to PPE use in this study may also reflect good personal protective equipment availability in healthcare facilities. By comparing adherence percentage to appropriate PPE use with adherence to 1-meter physical distancing, this study also showed that adherence percentage is higher in appropriate PPE use than 1-meter physical distancing. This result may suggest that it was more difficult to adhere to 1-meter physical distancing than wearing appropriate PPE. Furthermore, in the healthcare services context, most health services require direct interaction such as physical examination and medical procedures between the HCWs and patients.

The percentage of staff that received training after COVID-19 pandemic (78.1\%) was higher than before the COVID-19 pandemic (73.7\%) showed that the IPC training was indeed provided to the staff higher management. There was $12.9 \%$ of respondents had never received IPC training yet in this study, which might be explained by the new staff's factor. The rising number in COVID-19 cases since the pandemic hit Lahad Datu in March 2020, had caused a significant number of new HCWs to be allocated to Lahad Datu health services especially since September 2020 [20]. The aim of new staff deployment was to cater for the high health service demands caused by drastic rise of COVID-19 cases in Sabah. It is important to note that the length of employment or working experiences duration may have a significant influence especially on the attitude and practises of IPC training, but in our study most of the HCWs had less than 1 year work experience in Lahad Datu since they were just deployed since September 2020. A study conducted in Henan, China reported that correct practices for COVID-19 prevention were positively correlated with longer duration of working experience (Zhang et al., 2020). Zhang et al, (2020) also reported that $\mathrm{HCWs}$ with 5 to 9 years working experiences $(\mathrm{OR}=1.54 ; 95 \% \mathrm{CI} 1.16-2.05)$ and more than 9 years of working experiences $(\mathrm{OR}=0.73 ; 95 \% \mathrm{CI}$ $0.55-0.96)$ are more likely to have correct practices for COVID-19 prevention compared to HCWs with less than 5 years working experiences. This study in Henan showed that better work practices were found among those with longer working experiences.

Based on further analysis, four factors were able to predict COVID 19 infection among government healthcare workers in Lahad Datu, Sabah which were community-related exposure, healthcare-related exposure, has direct physical contact with $\mathrm{HCWs}$ with positive COVID-19 without wearing mask, and had IPC training after COVID-19 pandemic. Even though not all the individuals with COVID-19 exposure will be infected, this study showed that the probability of getting the infection is higher when we had the COVID-19 exposure, whether it was community-related or healthcare-related. Analysis of respondents that had COVID-19 exposure in our study showed more respondents had healthcare-related exposure compared to community-related exposure. Similar finding from a study among HCWs in COVID-19 designated facilities in Klang Valley, Malaysia also reported that the most of their respondents were having healthcare-related exposure (68.9\%) [19]; also in another study in designated teaching hospital in Malaysia which reported 1,418 (24.3\%) HCWs had COVID-19 exposure with $1,174(82.8 \%)$ had healthcare-related exposure in Malaysia [22]. Healthcare-related exposure is highest in all three (3) studies in Malaysia due to more healthcare workers' time spent in the work environment as Malaysia government policy enforces strict standard operating protocol in community and travel restriction within district and states. Also, increasing COVID-19 cases in Malaysia, especially since September 2020 till date (June 2021), makes it difficult for the HCWs to take a holiday or join any community activities, making most of their time spent in workplaces contributing to a higher percentage of healthcare-related exposure. COVID-19 exposure risk would always be higher among $\mathrm{HCW}$ s due to the nature of their jobs consistent with Kim et al, that reported HCWs were more likely to have COVID-19 exposure compared to the general community $(\mathrm{p}<0.001)$.

The HCWs with direct physical contact with other positive COVID-19 HCWs were more likely to get COVID-19 infection and this finding is consistent with Celebi et al, that reported being in the same space without wearing mask $(p<0.001)$ and eating together with other HCWs $(p=0.003$ ) are predictor for COVID-19 infection. This study also found that both adherence to PPE use and physical distancing were less practised among colleagues, and higher adherence in the community and during patient care. Direct contact includes skin to skin transmission from shaking hand or hugging and droplet transmission due to speaking together, cough or sneezing [23]. A study in Iran also showed 28/273 (10.3\%) positive COVID-19 HCWs were infected due to close interaction with other positive COVID-19 HCWs [24]. A study analysing four healthcare-associated COVID-19 outbreaks in a university hospital in Europe found the main reason for transmission was numerous unprotected contacts between infected HCWs [25]. Furthermore, undiagnosed positive COVID-19 HCWs may act as virus reservoirs and pose an infection risk to both colleagues and patients in the healthcare setting. This finding also highlighted the importance of incorporating new work culture with stricter infection control measure among $\mathrm{HCWs}$, such as wearing appropriate PPE and avoid direct 
physical interaction to prevent further COVID-19 transmission between them.

Also, this study showed that the presence of IPC training after the COVID-19 pandemic is predictor of COVID-19 infection. However, this might be attributed by other factors that were not studied in this study, such as the timing of IPC training whether it was in early pandemic or recently, frequency of IPC training and others. Only $78.2 \%$ of our study cohort received training, and higher COVID-19 infection prevalence among those who received training after the COVID-19 pandemic can be explained by the timing of the training given. Other factors that can be considered due to most of the IPC training was given in the early COVID-19 pandemic and the transferring staff factor. There are many transferring in and out HCWs from Lahad Datu due to posting after graduating, posting after completing houseman ship (among doctors), family reason, or educational purposes. This may also explain why only $78.2 \%$ of our study cohort received IPC training. More respondents who were infected despite having COVID-19 training might be caused by more of the HCWS that received training were despatched to work in the COVID-19 area; therefore, they had higher COVID-19 exposure. As most of our respondents were relatively young, the number of trainings received and working experience may also explain why there was a higher prevalence of COVID-19 infection among those who had received COVID-19 training. A study among frontline HCWs in Ethiopia found that HCWS with 21-30 years of work experience has a lesser risk of COVID-19 infection than HCWs who had less than one year of work experience $(\mathrm{AOR}=0.01$; 95\% CI 0.01-0.06) [26]. Young and new workers may have less training frequency compared to older and experienced HCWs. Repetitive training associated with better health procedures performance [27]. Relatively young cohort in our study that may had less training frequency may justify our finding on why there was higher risk of COVID-19 infection among HCWs with those received IPC training post COVID-19 pandemic

COVID-19 disease is a new known communicable disease that is just recognised in December 2019; there are still many unknown facts regarding this disease. Therefore, there would always new updates on this disease from time to times as one of the known updated recommendations by WHO is regarding mask use in the community which were only recommended in June 2020, three months after COVID-19 declared as a public health emergency in March [28]. In Malaysia, public mask use was first recommended from June 2020 before this strategy was made compulsory starting August 1, 2020, following WHO recommendation to prevent further COVID-19 spread [29]. This showed that the COVID-19 recommendation would be continuously be updated based on the newest researches and studies. A national study among nurses in Hong Kong also recommended additional and regular IPC training to minimise COVID19 infection risk [30]. Continuous IPC training would facilitate and improve infection control compliance and adherence to infection control protocol [31].

There were some limitations acknowledged in this study. Due to the current COVID-19 pandemic and travel restrictions during the study period, the investigators relied on online questionnaires to obtain information related to this study. This method may cause bias from low response rate as well as recall bias since self-reported questionnaire was used. Still, these issues can be resolved as the respondents may contact the investigator anytime during the data collection period, also the data from this study was also verified with respective person in charge from both hospital and primary healthcare facilities.

\section{CONCLUSION}

Community-related exposure, healthcare-related exposure, had direct physical contact with HCWs with positive COVID-19 without wearing PPE and had IPC training after COVID-19 pandemic is associated with increased risk of COVID-19 infection in this study. Healthcare workers are essential asset to ensure ongoing health system deliverance, thus designation of a safe working environment is a priority. Adherence and practising infection control knowledge by using appropriate PPE use and maintaining physical distance are some of the keys to reduce COVID-19 exposure in both community and healthcare, further reducing COVID-19 infection among healthcare workers. Restructuring the healthcare workers schedule more systematically is recommended to ensure fewer HCWs are taking break at the same time to achieve proper physical distancing. Since using a common crowded resting space may cause the healthcare workers to share interaction such as eating or speaking together without PPE, thus providing a suitable space for resting and eating is also an important measure to reduce healthcarerelated exposure. Providing regular and updated infection prevention and control (IPC) training to all healthcare workers in the services is recommended to increase knowledge towards good IPC practise. Also, doing field audit to assess the actual in-field IPC training application is also recommended to ensure adherence to IPC training.

Protecting healthcare workers from any communicable disease is a crucial step in maintaining health system capacity together reducing morbidity and mortality. Some recommendations on the research methodology can be endorsed for future research. Future researches are recommended to focus on understanding and determining the best infection control training method for healthcare workers to ensure improvement on adherence to infection control application, thus keeping both healthcare population as well community population healthy. 


\section{AUTHORS' CONTRIBUTIONS}

NSZ: wrote the paper with input and discussion from all authors, AAR, SAM, VG: co-conceptualized the paper, led to its writing and helped frame the analyses and result interpretation. All authors contributed to discussions and the writing of the manuscripts.

\section{ACKNOWLEDGMENTS}

The authors wish to thank the Director-General of Health Malaysia for granting the permission to publish this paper. The authors would like to express their gratitude and sincere appreciation to Universiti Putra Malaysia (UPM) in completing this work. Lastly, the authors would like to express sincere gratitude to all the healthcare workers of the hospital and primary healthcare settings in Lahad Datu, Sabah for their contributions to the study.

\section{REFERENCES}

[1] WHO, "WHO Coronavirus Disease (COVID-19) Dashboard | WHO Coronavirus Disease (COVID-19) Dashboard." 2021, Accessed: Jan. 03, 2021. [Online]. Available: https://covid19. who.int/?gclid=Cj0KCQiA0MD $\% 7 B \% 5 C \_\% 7 D B R C T A R I s A D X o o p a o W F g J s t t$ swOs9AokihX1Nk5ltx-

RRc5wQEfzZcBCpjzNqW9owLjMaAi0gEALw $\% 7 \mathrm{~B} \% 5 \mathrm{C} \_\% 7 \mathrm{DwcB}$.

[2] E. Ariza-Heredia et al., "Surveillance and Identification of Clusters of Health Care Workers with COVID-19: Multidimensional Interventions at a Comprehensive Cancer Center," Infect. Control Hosp. Epidemiol., p. 1, 2020, doi: 10.1017/ice.2020.1315.

[3] Z. Yuan, Y. Xiao, Z. Dai, J. Huang, Z. Zhang, and Y. Chen, "Modelling the effects of wuhan's lockdown during COVID-19, China," Bull. World Health Organ., 2020, doi: 10.2471/BLT.20.254045

[4] A. U. M. Shah et al., "COVID-19 outbreak in Malaysia: Actions taken by the Malaysian government," Int. J. Infect. Dis., 2020, doi: 10.1016/j.ijid.2020.05.093.

[5] MOH, "First confirmed nCOV case in Malaysia (Press Release)," MOH. Jan. 2020, [Online]. Available:

https://www.moh.gov.my/index.php/database\% 7B\%5C_\%7Dstores/store\%7B\%5C_\%7Dview $\% 7 B \% 5 C \_\% 7 D p a g e / 21 / 1301$.

[6] MOH, "Home | COVID-19 MALAYSIA," MOH. 2020, Accessed: Nov. 21, 2020. [Online]. Available: http://covid-19.moh.gov.my/.

[7] MOH, "COVID-19 Management Guidelines in
Malaysia," Nov. 2020. [Online]. Available: http://covid-19.moh.gov.my/garispanduan/garis-panduan-kkm.

[8] WHO, "Coronavirus Disease 2019 (COVID-19) Situation Report - 82,” 2020. [Online]. Available:

https://www.who.int/emergencies/diseases/nove 1-coronavirus-2019.

[9] G. Çelebi et al., "Specific risk factors for SARSCoV-2 transmission among health care workers in a university hospital," Am. J. Infect. Control, vol. 48, no. 10 , pp. 1225-1230, 2020, doi: 10.1016/j.ajic.2020.07.039.

[10] Z. Zhu, X. Lian, X. Su, W. Wu, G. A. Marraro, and Y. Zeng, "From SARS and MERS to COVID-19: A brief summary and comparison of severe acute respiratory infections caused by three highly pathogenic human coronaviruses," Respir. Res., vol. 21, no. 1, p. 224, Aug. 2020, doi: 10.1186/s12931-020-01479-w.

[11] MOH, "Annex 21: Management Of Healthcare Worker (HCW) During Covid-19 Pandemic," 2021. [Online]. Available: https://covid19.moh.gov.my/garis-panduan/garis-panduankkm/ANNEX_21_Mgmt_of_Healthcare_Worke rs_HCW_During_COVID-

19_Pandemic_30102021.pdf

[12] P. Galanis, I. Vraka, D. Fragkou, A. Bilali, and D. Kaitelidou, "Seroprevalence of SARS-CoV-2 antibodies and associated factors in healthcare workers: a systematic review and meta-analysis," J. Hosp. Infect., vol. 108, pp. 120-134, Feb. 2021, doi: 10.1016/j.jhin.2020.11.008.

[13] H. S. Ling et al., "COVID-19 Antibody Surveillance Among Healthcare Workers in A Non-COVID designated Cardiology Centre," Authorea Prepr., May 2020, doi: 10.22541/AU.158955330.06881415.

[14] JKNSabah, "Total COVID-19 cases in Sabah (4th August 2020).” JKN Sabah, 2020.

[15] MOH, "Malaysia Updates On the Coronavirus Disease 2019 (COVID-19) Situation in Malaysia (Press Release)." Putrajaya, Mar. 2020, [Online]. Available: http://covid19.moh.gov.my/terkini/032020/situasi-terkini13-mac-2020/52.

[16] Bernama, "Agong declares emergency in Batu Sapi Parliament, Sabah,” Bernama. Nov. 2020, [Online]. Available: https://www.bernama.com/bm/am/news.php?id $=1902631 \% 7 B \% 5 C \& \% 7 D f b c l i d=I w A R 3 p a r e r$ KlH8h6B1EcCgpgfEQ7BYyzDLXRwQkwS7o\%7B\%5C_\%7DmBS-qxYX0t7YM08g.

[17] J. Tan-Loh and B. Mun Keong Cheong, "A descriptive analysis of clinical characteristics of 
COVID-19 among healthcare workers in a district specialist hospital," Med. J. Malaysia, vol. 76, no. (1), pp. 24-28, 2021.

[18] K. Rachel et al., "Comparison of COVID-19 infections among healthcare workers and nonhealthcare workers," PLoS One, vol. 15, no. 12 December, p. e0241956, Dec. 2020, doi: 10.1371/journal.pone.0241956.

[19] Y. L. Woon et al., "Serology surveillance of SARS-CoV-2 antibodies among healthcare workers in COVID-19 designated facilities in Malaysia," Lancet Reg. Heal. - West. Pacific, vol. 9, p. 100123, Apr. 2021, doi: 10.1016/j.lanwpc.2021.100123.

[20] S. Atiqah, "MOH is sending doctors to Sabah," Berita Harian. Sep. 2020, [Online]. Available: https://www.bharian.com.my/berita/nasional/20 20/09/736999/kkm-hantar-pegawai-perubatanke-sabah.

[21] M. Zhang et al., "Knowledge, attitude, and practice regarding COVID-19 among healthcare workers in Henan, China," J. Hosp. Infect., vol. 105 , no. 2, p. 183, Jun. 2020, doi: 10.1016/J.JHIN.2020.04.012.

[22] K. S. Wan et al., "Safeguarding Healthcare Workers Amidst COVID-19: A Surveillance Programme in a Teaching Hospital in Malaysia," Bull. World Health Organ., 2020, doi: 10.2471/BLT.20.275214

[23] M. S. Islam et al., "Current knowledge of COVID-19 and infection prevention and control strategies in healthcare settings: A global analysis," Infect. Control Hosp. Epidemiol., vol. 41, no. 10, pp. 1196-1206, Oct. 2020, doi: 10.1017/ice.2020.237.

[24] G. Sabetian et al., "COVID-19 infection among healthcare workers: a cross-sectional study in southwest Iran," Virol. J., vol. 18, no. 1, p. 58, Dec. 2021, doi: 10.1186/s12985-021-01532-0.

[25] S. Schneider, B. Piening, P. A. Nouri-Pasovsky, A. C. Krüger, P. Gastmeier, and S. J. S. Aghdassi, "SARS-Coronavirus-2 cases in healthcare workers may not regularly originate from patient care: lessons from a university hospital on the underestimated risk of healthcare worker to healthcare worker transmission," Antimicrob. Resist. Infect. Control, vol. 9, no. 1, pp. 1-7, Dec. 2020, doi: 10.1186/s13756-020-00848-w.

[26] S. A. Atnafie, D. A. Anteneh, D. K. Yimenu, and Z. D. Kifle, "Assessment of exposure risks to COVID-19 among frontline health care workers in Amhara Region, Ethiopia: A cross-sectional survey," PLoS One, vol. 16, no. 4 April, p. e0251000, Apr. 2021, doi: 10.1371/journal.pone.0251000.
[27] H. M. Bosse et al., "The benefit of repetitive skills training and frequency of expert feedback in the early acquisition of procedural skills," BMC Med. Educ., vol. 15, no. 22, Dec. 2015, doi: 10.1186/s12909-015-0286-5.

[28] WHO, "Mask use in the context of COVID-19," Who, no. December, pp. 1-10, 2020, [Online]. Available:

https://www.who.int/publications/i/item/adviceon-the-use-of-masks-in-the-community-duringhome-care-and-in-healthcare-settings-in-thecontext-of-the-novel-coronavirus-(2019-ncov)outbreak.

[29] Bernama, "Compulsory mask use starting 1st August 2020," Bernama. Jul. 2020, [Online] Available:

https://bernama.com/bm/am/news\%7B\%5C_\%7 Dcovid-19.php?id=1865931

[30] E. L. Y. Wong et al., "Compliance with standard precautions and its relationship with views on infection control and prevention policy among healthcare workers during covid-19 pandemic," Int. J. Environ. Res. Public Health, vol. 18, no. 7, 2021, doi: 10.3390/ijerph18073420.

[31] M. E. Ashinyo et al., "Infection prevention and control compliance among exposed healthcare workers in COVID-19 treatment centers in Ghana: A descriptive cross-sectional study," PLoS One, vol. 16, no. 3 March, p. e0248282, Mar. 2021, doi: 10.1371/journal.pone.0248282. 